\title{
UJI EFIKASI BIOINSEKTISIDA JAMUR ENTOMOPATOGEN BERFORMULASI CAIR TERHADAP PLUTELLA XYLOSTELLA (L.) DI LABORATORIUM
}

\author{
Haperidah Nunilahwati', Siti Herlinda², Chandra Irsan², \\ Yulia Pujiastuti², Khodijah' ${ }^{1}, \&$ Dewi Meidelima ${ }^{3}$ \\ ${ }^{1}$ Fakultas Pertanian, Universitas Palembang. Jl. Darmapala No. I A. Bukit Besar. Palembang. 30139 \\ E-mail: haperidah@yahoo.com \\ ${ }^{2}$ Jurusan Hama dan Penyakit Tumbuhan, Fakultas Pertanian, Universitas Sriwijaya, \\ Jl.Raya Palembang-Prabumulih Km 32, Ogan Ilir, Inderalaya 30662 \\ ${ }^{3}$ Stiper Sriwigama. Jl. Demang 4. Demang Lebar Daun. Lorok Pakjo. Palembang. 30137.
}

\begin{abstract}
Efficacy test of liquid bio-insecticide of entomopathogenic fungi in control against Plutella xylostella in the laboratory. The insect pest $P$. xylostella could reduce crop production of Brassicaceae. The aim of research was to test the efficacy liquid bio insecticide with active ingredient of Beauveria bassiana and Metarhizium anisopliae fungi to control P.xylostella. Bioinsecticide was applied by spraying on mustard leaves infested with 50 individuals of third instar larvae of $P$. xylostella and a density of $1 \times 10^{6}$ conidia $\mathrm{ml}^{-1}$. Larval mortality was observed every 2 hours and $\mathrm{LT}_{50}$ of larvae was calculated. The study showed that the highest percentage of mortality found in Mt ES and Mt ES (cf) isolates was 99.6\%, the lowest mortality at Mt NES isolate was $96.80 \% . \mathrm{LT}_{50}$ and $\mathrm{LT}_{95}$ values BbES were the lowest i.e. 2.04 days and 2.95 days. The highest $\mathrm{LT}_{50}$ and $\mathrm{LT}_{95}$ of Mt NES isolate were 2.24 days and 3.32 days. The liquid bio-insecticide of entomopathogenic fungus B. bassiana and $M$. anisopliae were effective to control the larvae of $P$. xylostella.
\end{abstract}

Key words: B. bassiana, liquid bio-insecticide, M. anisopliae, P. xylostella.

\begin{abstract}
ABSTRAK
Uji efikasi bioinsektisida jamur entomopatogen berformulasi cair terhadap Plutella xylostella di laboratorium. Tingkat serangan P. xylostella sangat berpengaruh terhadap produksi tanaman famili Brassicaceae. Tujuan penelitian ialah untuk uji efikasi bioinsektisida cair yang berbahan aktif jamur B. bassiana dan M. anisopliae terhadap larva P. xylostella. Uji efikasi bioinsektisida cair pada serangga uji dilakukan dengan cara menyemprotkan tanaman caisin yang sudah mengandung 50 ekor larva P. xylostella instar tiga, dengan kerapatan konidia $1 \times 10^{6} \mathrm{konidia} / \mathrm{ml}$. LT ${ }_{50}$ larva diamati setiap 2 jam hingga larva yang mati mencapai 50\%. Hasil penelitian disimpulkan bahwa persentase mortalitas tertinggi terjadi pada Mt ES dan Mt ES(cf) yaitu 99,6\%, mortalitas terendah pada Mt NES yaitu 96,8\%. Nilai $\mathrm{LT}_{50}$ dan $\mathrm{LT}_{95}$ terendah pada BbES yaitu 2,04 hari dan 2,95 hari. Nilai $\mathrm{LT}_{50}$ dan $\mathrm{LT}_{95}$ tertinggi pada Mt NES yaitu 2,24 hari dan 3,32 hari. Hasil penelitian ini dapat disimpulkan bahwa bioinsektisida cair berbahan aktif jamur entomopatogen B. bassiana dan M. anisopliae efektif menekan populasi larva P. xylostella.
\end{abstract}

Kata kunci: B. bassiana,bioinsektisida cair, M. anisopliae, P. xylostella.

\section{PENDAHULUAN}

Serangan larva Plutella xylostella (L.) akan mengakibatkan daun tanaman berlubang dan tinggal tulang-tulang daunnya saja (Kalshoven, 1981). Persentase kerusakan yang disebabkan hama $P$. xylostella dapat mencapai 54-83\% (Wang et al., 2004). Pengendalian $P$. xylostella saat ini masih banyak menggunakan pestisida sintetik. Penggunaan pestisida sintetik tersebut dapat berpengaruh negatif pada produk pertanian. Salah satu alternatif pengendalian hama yang dapat mengurangi dampak negatif penggunaan pestisida ialah penggendalian hama secara hayati. Menurut Krutmuang \& Mekchay (2005), pengendalian hayati tidak akan merusak lingkungan dan tidak mematikan organisme non target.

Jamur entomopatogen merupakan agens hayati yang berpotensi mengendalikan serangga hama diantaranya jamur Beauveria bassiana (Cagan \& Svercel, 2001; Tafoya et al., 2004; Soetopo \& Indrayani, 2007; Deciyanto \& Indrayani, 2008; Herlinda, 2010) dan jamur Metarhizium anisopliae (Lomer et al., 2001; 
Wang \& Powell, 2002; Rodrigues et al., 2005; Sambiran \& Hosang, 2007; Ghanbary et al., 2009).

Konidia $B$. bassiana dapat menyebabkan mortalitas tungau mencapai 80-100\% (Deciyanto \& Indrayani, 2008), mortalitas Nezara viridula mencapai 70-76\% (Indriyati, 2009) dan mortalitas P. xylostella mencapai $83 \%$ dalam waktu 2,09 hari (Nunilahwati et al., 2012). Biopestisida M. anisopliae dapat mematikan Locusta mencapai 70-90\% dalam waktu 14-20 hari (Lomer et al., 2001), dan 8,39 hari (Widiarta \& Kusdiaman, 2007).

Konidia jamur entomopatogen $B$. bassiana yang diaplikasikan dapat berupa suspensi (tidak diformulasi), formulasi butiran, dan bentuk pellet, dan ketiganya memperlihatkan hasil pengendalian yang cukup nyata (Soetopo \& Indrayani, 2007). Selain itu juga konidia jamur entomopatogen dapat ditumbuhkan pada media buatan. Kandungan media buatan tersebut dapat mempengaruhi pertumbuhan dan perkembangan jamur B. bassiana dan M. anisopliae (Herlinda et al., 2008a). Menurut Soetopo \& Indrayani (2007), perbedaan kandungan nutrisi media buatan akan mempengaruhi produksi konidia jamur entomopatogen. Herlinda et al. (2006) menyatakan bahwa jamur $B$. bassiana dan $M$. anisopliae yang dibiakan dalam media buatan Glucose Yeast Agar (GYA) yang mengandung tepung jangkrik dan formulasi bioinsektisida cair yang ditambahkan Ekstrak Kompos Kulit Udang (EKKU) dapat meningkatkan kerapatan spora karena kaya akan kandungan khitin.

Penelitian ini bertujuan untuk menguji bioinsektisida cair yang berbahan aktif spora jamur $B$. bassiana dan $M$. anisopliae dalam mengendalikan $P$. xylostella.

\section{METODE PENELITIAN}

Tempat dan Waktu. Penelitian ini dilaksanakan di Laboratorium Entomologi Jurusan Hama dan Penyakit Tumbuhan Fakultas Pertanian Universitas Sriwijaya dari bulan September 2011 sampai Maret 2012.

Persiapan Isolat Jamur Entomopatogen. Isolat jamur entomopatogen yang akan digunakan pada penelitian ini adalah isolat jamur entomopatogen $B$. bassiana dan M. anisopliae. Perbanyakan isolat dengan menggunakan media GYA (Glucose Yeast Agar). Media GYA digunakan untuk perbanyakan biakan murni jamur entomopatogen. Komposisi media tersebut terdiri dari agar sebanyak $5 \mathrm{~g}$, yeast $1 \mathrm{~g}$, sukrosa $2,5 \mathrm{~g}$, tepung jangkrik sebanyak $1,25 \mathrm{~g}$, dan aquadest $250 \mathrm{ml}$. Selanjutnya bahan-bahan tersebut dicampur dan diaduk merata lalu dimasukan dalam erlenmeyer $250 \mathrm{ml}$ kemudian ditutup dengan allumunium foil dan distrerilisasi dalam otoklaf selama 20 menit dengan tekanan $1 \mathrm{~atm}$.

Setelah proses sterilisasi selesai media didinginkan kemudian ditambahkan antibiotik amoxcillin sebanyak 2 $\mathrm{g}$ dan dikocok merata. Media lalu dituangkan ke dalam cawan petri diameter $9 \mathrm{~cm}$ dengan ketebalan secukupnya, lalu inokulasi jamur entomopatogen $(B$. bassiana dan $M$. anisopliae) yang dilakukan dalam keadaan aseptik.

Persiapan Isolat Cair. Isolat yang digunakan untuk pembuatan isolat cair adalah isolat hasil perbanyakan dengan media GYA. Isolat cair yaitu dengan menggunakan media GYB (Glucose Yeast Broth). Komposisi media GYB adalah setiap $1000 \mathrm{ml}$ air steril dicampur dengan sukrosa $20 \mathrm{~g}$, yeast $20 \mathrm{~g}$, dan tepung jangkrik $5 \mathrm{~g}$. Campuran tersebut dimasukkan ke dalam gelas takar ukuran $1000 \mathrm{ml}$, lalu diaduk. Kemudian dimasukkan kedalam botol selai masing-masing $200 \mathrm{ml}$, sehingga dari $1000 \mathrm{ml}$ didapat 5 botol. Lalu tutup dengan aluminium foil dan plastik kemudian ikat dengan karet.

Botol selai yang telah berisi media GYB kemudian di otoklaf selama 20 menit dengan tekanan 1 atm. Setelah itu didiamkan selama 24 jam. Media GYB yang telah didiamkan selama 24 jam kemudian di reisolasi dengan jamur B. bassiana dan M. anisopliae yang berasal dari isolat padat GYA sebanyak 3 bor gabus ukuran $0,5 \mathrm{~cm}$. Lalu ditutup kembali dengan aluminium foil dan diikat dengan karet. Kegiatan ini dilakukan secara steril di ruang laminar air flow. Setelah itu botol selai yang berisi media GYB tersebut di-shaker selama 7 hari, kemudian diinkubasikan selama 7 hari.

Pembuatan Bioinsektisida Cair. Pembuatan bioinsektisida cair dilakukan dengan 2 cara: 1) EKKU (Ekstrak Kompos Kulit Udang) steril yaitu EKKU yang telah di otoklaf selama 20 menit dengan tekanan 1 atm, lalu di inkubasi selama 24 jam; 2) EKKU non steril yaitu EKKU yang tidak di otoklaf selama 20 menit dengan tekanan $1 \mathrm{~atm}$. Pembuatan bioinsektisida cair ini dibagi menjadi 4 bagian yaitu 1) EKKU steril $B$. bassiana, 2) EKKU steril $M$. anisopliae, 3) EKKU non steril $B$. bassiana, 4) EKKU non steril $M$. anisopliae.

Cara pembuatan bioinsektisida cair adalah EKKU (steril atau non steril) $100 \mathrm{~mL}$ ditambah GYB $600 \mathrm{ml}$ dan sukrosa $300 \mathrm{~g}$ dicampur lalu diaduk sampai larut, kemudian masukkan $10 \mathrm{ml}$ minyak sayur. Kemudian dimasukkan dalam botol plastik volume $1000 \mathrm{ml}$. Simpan selama 30 hari. Setelah 30 hari disimpan bioinsektisida diaplikasikan. 


\section{Pembuatan Bioinsektisida Cair dengan} Sentrifugasi. Bioinsektisida cair yang dibuat menggunakan jamur entomopatogen $B$. bassiana dan M. anisopliae. Media GYB sebanyak $600 \mathrm{ml}$ dicampur dengan $100 \mathrm{ml}$ EKKU yang telah disterilkan ditambahkan 300 gr sukrosa dan $10 \mathrm{ml}$ minyak sayur. Campuran bahan tersebut dimasukkan ke dalam botol berukuran $1000 \mathrm{ml}$, kemudian disimpan selama 30 hari. Setelah disimpan, larutan bioinsektisida tersebut diendapkan dengan alat centrifuge (kecepatan $10.000 \mathrm{rpm}$ ) selama 10 menit dengan suhu $4^{\circ} \mathrm{C}$. Bioinsektisida cair atau supernatan yang didapat digunakan untuk diaplikasikan ke serangga uji. Pengujian yang dilakukan untuk melihat tingkat patogenisitasnya.

Mortalitas Larva $P$. xylostella. Bioinsektisida formulasi cair yang telah disimpan selama 30 hari, kemudian diaplikasikan langsung dengan cara menyemprot tanaman caisin yang sudah mengandung larva instar tiga $P$. xylostella. Kerapatan yang diberikan ialah $1 \times 10^{6} \mathrm{konidia} / \mathrm{ml}$. Masing-masing perlakuan terdapat 50 ekor larva instar tiga $P$. xylostella dan masing-masing perlakuan di ulang sebanyak 5 kali. Untuk menentukan kematian larva dilakukan pengamatan setiap 2 jam selama fase larva, sedangkan jumlah larva yang membentuk pupa dan imago dicatat setiap hari hingga semua pupa menjadi imago.

Viabilitas Konidia. Sebelum perlakuan, diamati viabilitas konidia setiap formulasi bioinsektisida. Viabilitas konidia ditentukan setelah suspensi konidia diinkubasikan selama 24 jam. Satu tetes suspensi diteteskan pada kaca preparat dan ditutup dengan gelas penutup. Kemudian jumlah konidia yang berkecambah dan yang tidak berkecambah dihitung. Perhitungannya dilakukan pada bidang pandang di bawah mikroskop dengan perbesaran 400x. Variabel daya kecambah dinyatakan dengan persentase jumlah konidia yang berkecambah dengan menggunakan rumus Gabriel dan Riyatno (1989) sebagai berikut:

$$
\mathrm{V}=\frac{\mathrm{g}}{\mathrm{g}+\mathrm{u}} \times 100 \%
$$

Keterangan:

$\mathrm{V}=$ perkecambahan spora (viabilitas)

$\mathrm{g}=$ jumlah spora yang berkecambah

$\mathrm{u}=$ jumlah spora yang tidak berkecambah

LT $_{50}$ dan LT $_{95}$ Larva $P$. xylostella. Pengamatan dilakukan bersamaan dengan pengamatan mortalitas larva. Pengamatan dilakukan setiap 2 jam sekali sejak perlakuan bioinsektisida formulasi cair dilakukan, dengan menghitung waktu yang dibutuhkan dari perlakuan untuk mematikan 50\% dan $95 \%$ larva P. xylostella. Larva $P$. xylostella yang mati karena $B$. bassiana dicirikan adanya perubahan warna tubuh larva dari hijau menjadi hijau kekuningan dan akhirnya menjadi cokat kehitaman. Tubuh larva mengkerut, keras, kaku, dan diselimuti miselia berwarna putih (Herlinda, 2005), sedangkan gejala awal infeksi $M$. anisopliae tidak terlihat pertumbuhan konidia. Beberapa hari kemudian akan tumbuh miselia di permukaan tubuh serangga (Kabaluk et al., 2001)

Analisis Data. Data perbedaan persentase mortalitas larva dan persentase larva menjadi pupa, viabilitas konidia, antar perlakuan dibandingkan menggunakan Analysis of Varience (ANOVA). Percobaan masingmasing perlakuan disusun menggunakan Rancangan Acak Lengkap (RAL). Waktu kematian larva dianalisis menggunkan $\mathrm{LT}_{50}$ dan $\mathrm{LT}_{95}$ yang perhitungannya menggunakan analisis probit waktu kematian larva dengan program SAS-STAT pada SAS 6.12.

\section{HASIL DAN PEMBAHASAN}

Mortalitas Larva $P$. xylostella. Mortalitas larva $P$. xylostella tertinggi terjadi pada 3,5 hari setelah aplikasi bioinsektisida cair. Persentase mortalitas larva $P$. xylostella tertinggi pada perlakuan bioinsektisida cair berbahan aktif $B$. bassiana (Bb ES dan Bb NES) yaitu 99,2\% dan terendah (Bb ES(cf)) yaitu 98,00\%, sedangkan persentase mortalitas larva $P$. xylostella tertinggi pada perlakuan bioinsektisida cair berbahan aktif M. anisopliae (Mt ES dan Mt ES(cf)) yaitu 99,6\% dan terendah (Mt NES) yaitu 96,80\% (Tabel 1).

Tetapi, hasil analisis sidik ragam menunjukkan bahwa persentase mortalitas larva $P$. xylostella yang diaplikasikan bioinsektisida cair berbahan aktif $B$. bassiana dan $M$. anisopliae pada semua perlakuan adalah tidak berbeda nyata. Hasil penelitian Effendy et $a l$. (2010) menunjukkan bahwa jamur $B$. bassiana dan $M$. anisopliae berpengaruh tidak berbeda nyata terhadap mortalitas nimfa walang sangit. Begitu juga hasil penelitian Nunilahwati et al. (2012) di laboratorium menunjukkan isolat BPluS yang berasal dari jamur Beauveria dapat menyebabkan kematian $P$. xylostella sebesar $83 \%$, dan isolat MAgPd yang berasal dari jamur M. anisopliae sebesar $82 \%$.

Hal ini berarti bioinsektisida cair berbahan aktif B. bassiana dan $M$. anisopliae virulen terhadap larva $P$. xylostella, dan mengindikasikan bahwa jamur entomopatogen sangat efektif dan berpotensi dalam 
Tabel 1. Rata-rata mortalitas larva P. xylostella setelah 3,5 hari diaplikasikan bioinsektisida cair berbahan aktif $B$. bassiana dan M. anisopliae

\begin{tabular}{lc}
\hline Bioinsektisida & Mortalitas larva (\%) \\
\hline B. bassiana + EKKU steril (Bb ES) & $99,20 \mathrm{a}$ \\
M. anisopliae + EKKU steril (Mt ES) & $99,60 \mathrm{a}$ \\
B. bassiana + EKKU non steril (Bb NES) & $99,20 \mathrm{a}$ \\
M. anisopliae + EKKU non steril (Mt NES) & $96,80 \mathrm{a}$ \\
B. bassiana + EKKU steril disentrifugasi (10 menit) (Bb ES(cf)) & $98,00 \mathrm{a}$ \\
M. anisopliae + EKKU steril disentrifugasi (10 menit) (Mt ES(cf)) & $99,60 \mathrm{a}$ \\
Air steril (Kontrol) & $0,00 \mathrm{~b}$ \\
\hline
\end{tabular}

Angka diikuti oleh huruf yang sama tidak berbeda nyata berdasarkan uji BNJ pada alpa 0.05 .

mengendalikan serangga hama. Herlinda et al. (2008b) menyatakan bahwa B. bassiana dan M. anisopliae merupakan jamur entomopatogen yang terbaik dan efektif dalam mematikan nimfa wereng coklat.

Mortalitas larva $P$. xylostella setelah perlakuan bioinsektisida cair berbahan aktif $B$. bassiana dan $M$. anisopliae untuk semua perlakuan, mulai terjadi pada hari pertama. Laju mortalitas larva $P$. xylostella terus meningkat dan mencapai puncaknya pada hari ke-3, dengan kisaran 98,00-99,20\% untuk B. bassiana dan 96,80-99,6\% untuk M. anisopliae. Pada hari ke-4 mortalitas menurun (Gambar 1).

Mortalitas larva P. xylostella dari perlakuan diduga karena kontak langsung bioinsektsida pada tubuh larva dan adanya kandungan media serta bahan aktif yang berbeda dari masing-masing perlakuan. Surtikanti \& Yasin (2009) menyatakan bahwa pada saat terjadi kontak, spora membentuk tabung kecambah dan mensekresikan enzim untuk melunakkan kutikula larva sehingga spora dapat menembus masuk ke dalam tubuh larva. Menurut Herlinda (2010), perbedaan mortalitas serangga inang oleh jamur entomopatogen karena adanya perbedaan viabilitas dan virulensi konidia.

Faktor suhu dan kelembaban juga dapat mempengaruhi perkembangan jamur $B$. bassiana dan M. anisopliae. Suhu rata-rata $28,36{ }^{\circ} \mathrm{C}$ dan kelembaban nisbi udara relatif $85,35 \%$ di ruangan penelitian mendukung kehidupan dan perkembangan jamur $B$. bassiana dan M. anisopliae. Sheroze et al. (2003) menyatakan bahwa suhu $30{ }^{\circ} \mathrm{C}$ dan kelembaban relatif $80 \%$ merupakan kondisi yang baik untuk pertumbuhan jamur B. bassiana dan M. anisopliae. Sedangkan menurut Bukhari et al. (2010), mortalitas serangga yang disebabkan jamur entomopatogen disebabkan karena faktor-faktor seperti karakteristik larva yaitu spesies, umur dan kepadatan larva, jenis dan konsentrasi jamur entomopatogen serta pengaruh lingkungan.
Larva menjadi Pupa. Larva membentuk pupa terjadi pada lima hari setelah aplikasi bioinsektisida cair. Persentase larva $P$. xylostella menjadi pupa tertinggi pada perlakuan bioinsektisida cair berbahan aktif $B$. bassiana (Bb ES(cf)) yaitu 2,0\% dan terendah (Bb ES) yaitu $0,8 \%$, sedangkan persentase larva $P$. xylostella menjadi pupa tertinggi pada perlakuan bioinsektisida cair berbahan aktif $M$. anisopliae (Mt NES) yaitu 3,2\% dan terendah (Mt ES dan Mt ES(cf)) yaitu 0,4\%, (Tabel 2). Tetapi dari analisis sidik ragam untuk persentase larva $P$. xylostella menjadi pupa pada semua perlakuan adalah tidak berbeda nyata.

Menurut Herlinda et al. (2005), pada umumnya larva $P$. xylostella yang diaplikasikan dengan konidia $B$. bassiana mengalami kematian tetapi masih ditemukan larva menjadi pupa dan imago tetapi cacat dan mati. Adanya larva yang masih dapat membentuk pupa, menurut Rath et al. (1996) karena larva memiliki kemampuan untuk mencegah infeksi yang disebabkan oleh jamur entomopatogen. Disamping itu pula menurut Prayogo (2006), karena mobilitas serangga dan adanya peristiwa ganti kulit memasuki fase berikutnya menyebabkan tidak semua konidia jamur entomopatogen yang diaplikasikan berhasil mencapai sasaran. Tetapi pupa yang terbentuk tidak ada yang menjadi imago. Hal ini karena jamur entomopatogen memiliki kemampuan infeksi yang tinggi (Tafoya et al., 2004), dan adanya EKKU sebagai bahan pembawa (carrier) yang dapat mempertahankan keefektifan bioinsektisida cair berbahan aktif $B$. bassiana dan $M$. anisopliae (Suwandi, 2004; Herlinda et al., 2008a), karena EKKU mengandung khitin dapat meningkatkan virulensi dan kerapatan konidia (Herlinda et al., 2006). Menurut Akbar et al. (2005), jamur entomopatogen yang tumbuh pada media cair menghasilkan mycotoksin dan konidia yang memiliki viabilitas dan virulensi tinggi. Disamping itu pula menurut Prayogo (2006) bahan pembawa (carrier) sebagai makanan cadangan (starter) bagi 


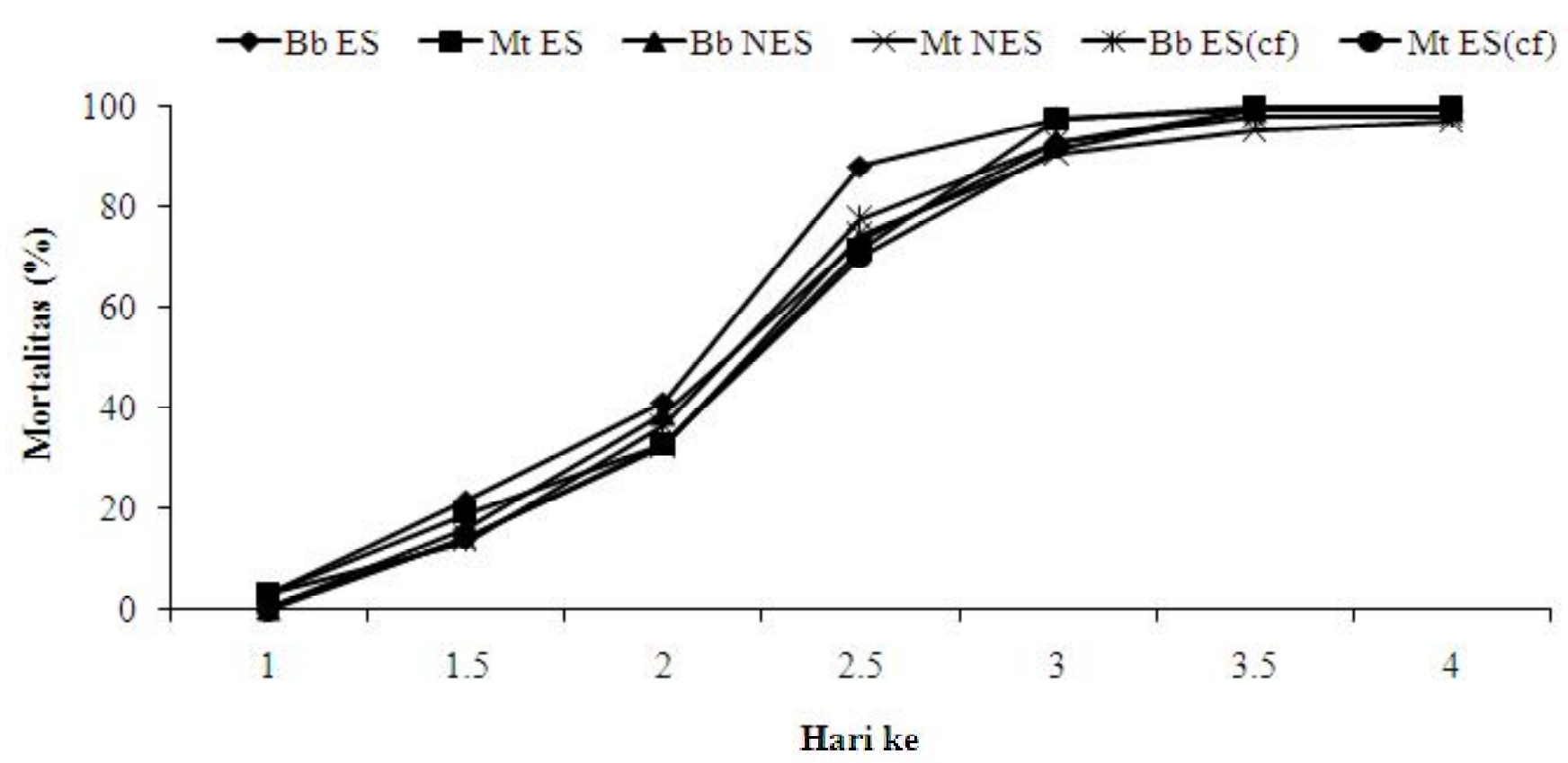

Gambar 1. Rata-rata mortalitas Plutella xylostella setelah aplikasi bioinsektisida cair.

Tabel 2. Rata-rata larva $P$. xylostella menjadi pupa setelah 5 hari diaplikasikan bioinsektisida cair berbahan aktif B. bassiana dan M. anisopliae

\begin{tabular}{lcc}
\hline Bioinsektisida & Larva menjadi pupa (\%) & Keterangan \\
\hline B. bassiana + EKKU steril (Bb ES) & $0,8 \mathrm{~b}$ & $\mathrm{Ph}$ \\
M. anisopliae + EKKU steril (Mt ES) & $0,4 \mathrm{~b}$ & $\mathrm{Ph}$ \\
B. bassiana + EKKU non steril (Bb NES) & $0,8 \mathrm{~b}$ & $\mathrm{Ph}$ \\
M. anisopliae + EKKU non steril (Mt NES) & $3,2 \mathrm{~b}$ & $\mathrm{Ph}$ \\
B. bassiana + EKKU steril disentrifugasi & $2,0 \mathrm{~b}$ & $\mathrm{Pk}$ \\
(10 menit) (Bb ES(cf)) & & \\
M. anisopliae + EKKU steril disentrifugasi & $0,4 \mathrm{~b}$ & $\mathrm{Pk}$ \\
(10 menit) (Mt ES(cf)) & $100 \mathrm{a}$ & $\mathrm{Pi}$ \\
Air steril (Kontrol) & & \\
\hline
\end{tabular}

$\mathrm{Ph}=$ pupa ditumbuhi hifa jamur dan mati, $\mathrm{Pk}=$ pupa cacat dan mati, $\mathrm{Pi}=$ pupa menjadi imago. Angka iikuti oleh huruf yang sama pada kolom yang sama tidak berbeda nyata.
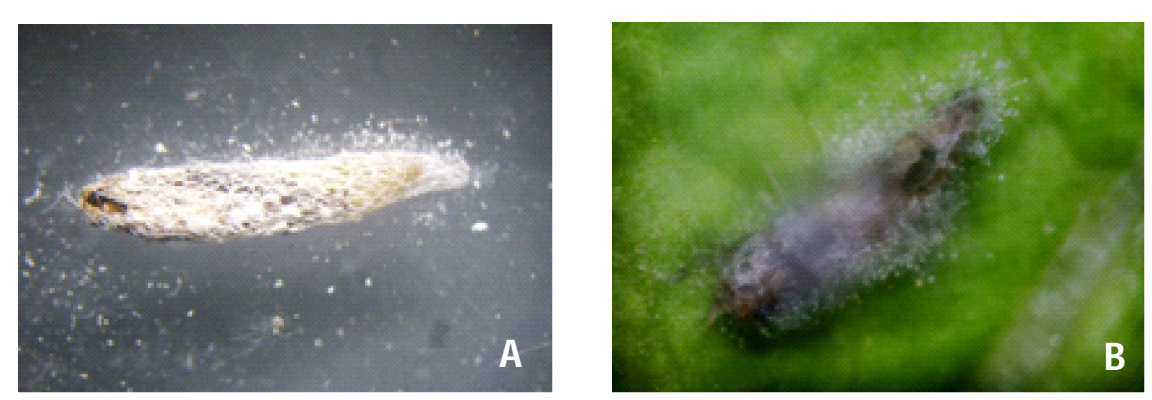

Gambar 2. Gejala pada pupa P. xylostella oleh jamur B. bassiana (a) dan M. anisopliae (b), 9 hari setelah aplikasi bioinsektisida cair 
konidia sebelum berhasil menginfeksi serangga. Dengan demikian, konidia yang gagal menginfeksi serangga masih dapat bertahan dengan makanan cadangan.

Pupa yang terbentuk menunjukkan gejala cacat, ditumbuhi jamur dan mati (Gambar 2). Gejala yang ditimbulkan pada pupa akibat $B$. bassiana adalah warna pupa menjadi hitam dan tampak massa konidia berwarna putih dan berwarna kehijauan untuk $M$. anisopliae yang meliputi pupa. Menurut Soetopo \& Indrayani (2007), miselia dan konidia $B$. bassiana berwarna putih dan dikenal sebagai white muscardine, sedangkan miselia dan konidia M. anisopliae berwarna hijau (Krutmuang \& Mekchay, 2005).

Viabilitas Konidia. Viabilitas konidia jamur entomopatogen dari bioinsektisida cair yang diaplikasikan cukup bervariasi. Viabilitas konidia tertinggi pada bioinsektisida cair berbahan aktif $M$. anisopliae (Mt ES) yaitu 23,49\% dan terendah (Mt ES(cf)) yaitu $16,24 \%$. Viabilitas konidia tertinggi pada bioinsektisida cair berbahan aktif B. bassiana (Bb ES) yaitu 23,49\% dan terendah (Bb NES) yaitu 19,66 (Tabel 3).

Konidia jamur entomopatogen yang berada dalam formulasi cair cenderung memiliki viabilitas lebih tinggi dibandingkan pada media padat sehingga virulensi dapat meningkat (Hasyim et al., 2005), tetapi menurut Soetopo (2004), penyebab utama tingginya mortalitas serangga inang adalah faktor bawaan dari strain jamur tersebut.
Perbedaan viabilitas konidia dapat disebabkan oleh media biakan (Herlinda et al., 2006), suhu dan kelembaban (Sheroze et al., 2003; Prayogo et al., 2005) serta faktor genetik (Nuraida \& Hasyim, 2009).

$\mathrm{LT}_{50}$ dan $\mathrm{LT}_{95}$ Larva $P$. xylostella. $\mathrm{LT}_{50}$ dan $\mathrm{LT}_{95}$ merupakan batas waktu yang dibutuhkan oleh suatu zat untuk membunuh 50 dan 95\% serangga uji. Hasil penelitian menunjukkan $\mathrm{LT}_{50}$ tersingkat terdapat pada bioinsektisida berbahan aktif $B$. bassiana (Bb ES) yaitu 2,04 hari, terlama pada bioinsektisida berbahan aktif $M$. anisopliae (Mt NES) yaitu 2,24 hari begitu juga untuk $\mathrm{LT}_{95}$ tersingkat terdapat pada bioinsektisida berbahan aktif $B$. bassiana (Bb ES) yaitu 2,95 hari, terlama pada bioinsektisida berbahan aktif $M$. anisopliae (Mt NES) yaitu 3,32 hari (Tabel 4).

Menurut Vijayavani et al. (2009), jamur $B$. bassiana dapat menyebabkan $100 \%$ mortalitas larva S. litura dalam waktu 5 hari pada kondisi laboratorium, sedangkan dari hasil penelitian Nunilahwati et al. (2012) isolat jamur Beuveria dapat menyebabkan $83 \%$ mortalitas P. xylostella dalam waktu 2,09 hari dan isolat jamur Metarhizium dapat menyebabkan $82 \%$ mortalitas P. xylostella dalam waktu 2,26 hari pada kondisi laboratorium. Jamur entomopatogen yang ditumbuhkan pada media cair dapat meningkatkan kematian dan nilai $\mathrm{LT}_{50}$ lebih singkat (Herlinda et al., 2008b). Herlinda et al. (2006) menyatakan bahwa semakin rendah nilai $\mathrm{LT}_{50}$ semakin virulen isolat karena itu nilai $\mathrm{LT}_{50}$ dapat menentukan potensi isolat tersebut. Artinya bioinsektisida

Tabel 3. Viabilitas konidia jamur entomopatogen dari bioinsektisida cair yang diaplikasikan pada larva $P$. xylostella

\begin{tabular}{lc}
\hline Bioinsektisida & Viabilitas konidia (\%) \\
\hline Bb ES & 23,49 \\
Mt ES & 27,87 \\
Bb NES & 19,66 \\
Mt NES & 22,15 \\
Bb ES(cf) & 20,08 \\
Mt ES(cf) & 16,24 \\
\hline
\end{tabular}

Tabel 4. $\mathrm{LT}_{50}$ dan $\mathrm{LT}_{95}$ dari larva P. xylostella setelah aplikasi bioinsektisida cair berbahan aktif $B$. bassiana dan M. anisopliae

\begin{tabular}{lcccccc}
\hline \multirow{2}{*}{ Bioinsektisida } & \multicolumn{3}{c}{ LT $_{50}$ (hari) } & \multicolumn{3}{c}{ LT $_{95}$ (hari) } \\
\cline { 2 - 7 } & Rata-rata & Terendah & Tertinggi & Rata-rata & Terendah & Tertinggi \\
\hline Bb ES & 2,04 & 2,00 & 2,09 & 2,95 & 2,87 & 3,04 \\
Mt ES & 2,10 & 2,06 & 2,14 & 3,01 & 2,94 & 3,10 \\
Bb NES & 2,15 & 2,12 & 2,18 & 3,08 & 3,04 & 3,13 \\
Mt NES & 2,24 & 2,20 & 2,28 & 3,32 & 3,25 & 3,39 \\
Bb ES(cf) & 2,14 & 2,11 & 2,17 & 3,13 & 3,03 & 3,18 \\
Mt ES(cf) & 2,21 & 2,18 & 2,24 & 3,15 & 3,10 & 3,20 \\
\hline
\end{tabular}


cair berbahan aktif $B$. bassiana dan M. anisopliae cukup efektif dan virulen dalam mematikan larva $P$. xylostella. Hal ini karena menurut Hasyim et al. (2005) jamur entomopatogen yang tumbuh pada media cair selain menghasilkan mikotoksin juga menghasilkan konidia dengan viabilitas lebih tinggi dan lebih virulens dibandingkan yang dibiakan pada media padat. Tetapi hasil penelitian Purwar \& Sachan (2005) mencatat bahwa $B$. bassiana lebih virulen dibandingkan $M$. anisopliae pada hama Spodoptera spp..

Menurut Herlinda et al. (2008a), jamur entomopatogen $B$. bassiana dan $M$. anisopliae dapat digunakan sebagai bahan aktif bioinsektisida cair karena sangat efektif dan memiliki kemampuan paling tinggi dalam mematikan wereng. Keefektifan jamur entomopatogen dalam menginfeksi inang dapat dipengaruhi oleh kerapatan konidia, frekuensi aplikasi, umur inang, waktu penyimpanan jamur entomopatogen (Prayogo et al., 2005), dan media biakan (Herlinda et al., 2006).

\section{SIMPULAN}

Persentase mortalitas tertinggi pada penelitian ini terdapat pada Mt ES dan Mt ES(cf) yaitu 99,60\%, mortalitas terendah pada Mt NES yaitu $96,8 \%$. Nilai $\mathrm{LT}_{50}$ dan $\mathrm{LT}_{95}$ terendah pada Bb ES yaitu 2,04 hari dan 2,95 hari. Nilai $\mathrm{LT}_{50}$ dan $\mathrm{LT}_{95}$ tertinggi pada Mt NES yaitu 2,24 hari dan 3,32 hari. Hasil penelitian ini dapat disimpulkan bahwa bioinsektisida cair berbahan aktif jamur entomopatogen $B$. bassiana dan $M$. anisopliae efektif dan berpengaruh terhadap mortalitas larva $P$. xylostella.

\section{DAFTAR PUSTAKA}

Akbar W, Lord JC, Nechols JR, \& Loughin TM. 2005. Efficacy of Beauveria bassiana for red flour beetle when applied with plant essential oils or in mineral oil and organosilicone carriers. J. Econ. Entomol. 98(3):683-688.

Bukhari T, Middelman A, Koenraadt CJM, Takken W, $\&$ Knols BGJ. 2010. Factors affecting fungusinduced larval mortality in Anopheles gambiae and Anopheles stephensi. J. Malaria. 9(1):115.

Cagan L \& Svercel M. 2001. The influence of ultraviolet light on pathogenicity of Entomopathogenic fungus Beauveria bassiana (Balsamo) Vuillemin to the European corn borer, Ostrinia nubilalis HBN (Lepidoptera: Crambidae). J. Cent. Europ. Agric. 2(4):227-234.
Deciyanto S \& Indrayani IGAA. 2008. Jamur entomopatogen Beauveria bassiana: potensi dan prospeknya dalam pengendalian hama tungau. Perspektif. 8(2):65-73.

Effendy TA, Septiadi R, Salim A, \& Mazid A. 2010. Jamur entomopatogen asal tanah lebak di Sumatera Selatan dan potensinya sebagai agensia hayati walang sangit (Leptocorisa oratorius (F.)). J. HPT Tropika 10(2):154-161.

Gabriel BP \& Riyatno. 1989. Metarhizium anisopliae (Metch) Sor: Taksonomi, Patologi, Produksi dan Aplikasinya. Jakarta: Direktorat Perlindungan Tanaman Perkebunan, Departemen Pertanian.

Ghanbary MAT, Asgharzadeh A, Hadizadeh AR, \& Sharif MM. 2009. A quick method for Metarhizium anisopliae isolation from cultural soils. Americ. J. Agric. Biol. Scien. 4(2):152155.

Hasyim A, Yasir H, \& Azwana. 2005. Seleksi substrat untuk perbanyakan Beauveria bassiana (Bals.) Vuill. Dan infektivitasnya terhadap hama penggerek bonggol pisang, Cosmopolites sordidus Germar. J. Hort. 15(2):116-123.

Herlinda S. 2005. Jenis dan kelimpahan parasitoid Plutella xylostella (L.) (Lepidoptera: Plutellidae) di Sumatera Selatan. J. Agria. 1(2):78-83.

Herlinda S, Sari EM, Pujiastuti Y, Suwandi, Nurnawati E, \& Riyanta A. 2005. Variasi virulensi strainstrain Beauveria bassiana (Bals.) Vuill. terhadap larva Plutella xylostella (L.) (Lepidoptera: Plutellidae). J. Agritrop. 24(2):52-57.

Herlinda S, Utama MD, Pujiastuti Y, \& Suwandi. 2006. Kerapatan dan viabilitas spora Beauveria bassiana (Bals.) Vuill akibat subkultur dan pengayaan media, serta virulensinya terhadap larva Plutella xylostella (Linn.). J. HPT Trpika 6(2):70-78.

Herlinda S, Mulyati SI, \& Suwandi. 2008a. Jamur entomopatogen berformulasi cair sebagai bioinsektisida untuk pengendali wereng coklat. $J$. Agritrop. 27(3):119-126.

Herlinda S, Hartono, \& Irsan C. 2008b. Efikasi bioinsektisida formulasi cair berbahan aktif Beauveria bassiana (Bals.)Vuill dan Metarhizium sp pada wereng punggung putih Sogatella furcifera (Horv.). Seminar Nasional dan Kongres PATPI; Palembang, 14-16 Okt 2008. 
Herlinda S. 2010. Spore density and viability of entomopathogenic fungal isolates from Indonesia, and their virulence against Aphis gossypii Glover (Homoptera: Aphididae). J. Tropic. Life Scien. Res. 21(1):13-21.

Indriyati. 2009. Virulensi jamur entomopatogen Beauveria bassiana (Balsamo) Vuillemin (Deuteromycotina, Hyphomycetes) terhadap kutudaun (Aphis spp) dan kepik hijau (Nezara viridula). J. HPT Tropika 9(2):92-98.

Kabaluk T, Goettel M, Vernon B, \& Noronha C. 2001. Evaluation of Metarhizium anisopliae as a biological control for wireworms. Organic Agriculture Centre of Canada. http://oacc.info/ ResearchDatabase/res_biol_ctrl_wireworms.asp (sitasi 23 Juni 2012).

Kalshoven LGE. 1981. The Pests of Crops In Indonesia. PT. Ichtiar Baru. Jakarta.

Krutmuang P \& Mekchay S. 2005. Pathogenicity of entomopathogenic fungi Metarhizium anisopliae against termites. Conference on International Agricultural Research for Development. Stuttgart-Hohenheim, Oct 11-13, 2005.

Lomer CJ, Bateman RP, Johnson DL, Langewald J, \& Thomas M. 2001. Biological control of locusts and grasshoppers. Annu. Rev. Entomol. 46:667702.

Nunilahwati H, Herlinda S, Irsan C, \& Pujiastuti Y. 2012. Eksplorasi, isolasi dan seleksi jamur entomopatogen Plutella xylostella (Lepidoptera: Yponomeutidae) pada pertanaman caisin (Brassica chinensis) di Sumatera Selatan. J. HPT Tropika 12(1):1-11.

Nuraida \& Hasyim A. 2009. Isolasi, identifikasi, dan karakteristik jamur entomopatogen dari rizosfir pertanaman kubis. J. Hort. 19(4):419-432.

Prayogo Y, Tengkano W, \& Marwoto. 2005. Prospek cendawan entomopatogen Metarhizium anisopliae untuk mengendalikan ulat grayak Spodoptera litura pada kedelai. J. Litbang. Pertan. 24(1):19-26.

Prayogo Y. 2006. Upaya mempertahankan keefektifan cendawan entomopatogen untuk mengendalikan hama tanaman pangan. J. Libang Pertanian. 25(2):47-54.
Purwar P \& Sachan GC. 2005. Biotoxicity of Beauveria bassiana and Metarhizium anisopliae against Spodoptera litura and Spilarctia oblique. Ann. Plant. Protec. Scien. 13(2):360-364.

Rath AC, Guy PL, \& Webb UY. 1996. Metarhizium anisopliae surface antigens are correlated with pathoginicity. J. Mycol. Res. 100(1):57-62.

Rodrigues S, Paveling R, Nagel P, \& Keller S. 2005. The natural distribution of the entomopathogenic soil fungus Metarhizium anisopliae in different regions and habitat types in Switzerland. Insect Pathogens and Insect Parasitic Nematodos: Melolontha. Bull. IOBC/WPRS. 28(2):185-188.

Sambiran WJ \& Hosang MLA. 2007. Pertumbuhan cendawan Metarhizium anisopliae (Metch) Sorokin pada media air kelapa. Bul. Palma. 33:917.

Sheroze A, Rashid A, Shakir AS, \& Khan SM. 2003. Effect of bio-control agents on leaf rustof wheat and influenceof different temperature and humidity levels on their colony growth. Int. J. Agri. Biol. 5(1):83-85.

Soetopo D. 2004. Efficacy of selected Beauveria bassiana (Bals.) Vuill. Isolates in combination with a resistant cotton variety (PSB-Ct 9) againts the cotton bollworm, Helicoverpa armigera (Hübner) (Lepidoptera: Noctuidae). [Disertasi]. Philippines: University of The Philippines Los Banos.

Soetopo D \& Indrayani IGAA. 2007. Status teknologi dan prospek Beauveria bassiana untuk pengendalian serangga hama tanaman perkebunan yang ramah lingkungan. Perspektif. 6(1):29-46.

Surtikanti \& Yasin M. 2009. Keefektifan entomopatogenik Beauveria bassiana Vuill. dari berbagai media tumbuh terhadap Spodoptera litura F.(Lepidoptera: Noctuidae) di laboratorium. Prosiding Seminar Nasional Serealia; Maros, 29 Jul 2009. hlm.358-362.

Suwandi. 2004. Effectiveness of shrimps shell compost extract for suppression of leaf diseases on cowpea, chili pepper and cabbage. J. Pest Tropic. 1(1):18-25 
Tafoya F, Zuniga-Delgadillo M, Alatorre R, CibbrianTovar J, \& Stanley D. 2004. Pathogenicity of Beauveria bassiana (Deuteromycota: Hyphomycetes) against the cactus weevil, Metamasius spinolae (Coleoptera: Curculionidae) under laboratory conditions. $J$. Florida Entomol. 87(4):533-536.

Vijayavani S, Reddy KRK, \& Murthy GBVN. 2009. Pathogenicity of Beauveria bassiana (Deut eromycotina: Euterom y cotina: Hyphomycetes) strains on Spodoptera litura (Fab.). J. Biopest. 2(2):205-207.

Wang C \& Powell JE. 2002. Isolation and Evaluation of Beauveria bassiana for control of Coptotermes formosanus and Reticulitermes flavipes (Isoptera: Rhinotermitidae). J. Sociobiol. 41(1):1-13.
Wang XG, Duff J, Keller MA, Zalucki MP, Liu SS, \& Bailey P. 2004. Role of Diadegma semiclausum (Hymenoptera: Ichneumonidae) in controlling Plutella xylostella (Lepidoptera: Plutellidae): cage exclusion experiments and direct observation. J. Biocontrol. Scienc. Tech. 14(6):571-586.

Widiarta IN \& Kusdiaman D. 2007. Penggunaan jamur entomopatogen Metarhizium anisopliae dan Beauveria bassiana untuk mengendalikan populasi wereng hijau. Penelitian Pertanian Tanaman Pangan. 26(1):46-54. 